\title{
Histological and Ultra Structure Observations of the Adrenal Gland of Fruit Eating Bat (Rousettus Aegyptiacus)
}

\author{
Atteyat Selim*, Eman Elnahass and Sara Ebrahim \\ Department of Zoology, Tanta University, Egypt \\ *Corresponding author: Atteyat Selim, Department of Zoology, Faulty of Science, Tanta University, Egypt. \\ To Cite This Article: Atteyat Selim. Histological and Ultra Structure Observations of the Adrenal Gland of Fruit Eating Bat (Rousettus Aegyptiacus). \\ Am J Biomed Sci \& Res. 2019 - 5(6). AJBSR.MS.ID.000961. DOI: 10.34297/AJBSR.2019.05.000961.
}

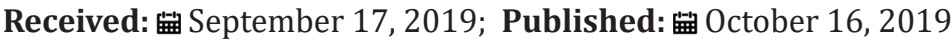

\begin{abstract}
In Rousettus aegyptiacus, gland has two layers: cortex and medulla. Three layers of cortex distributed equally as seen with histological structure. Ultra-structural observations of the glomerulosa cells give mitochondria with vesicular cristae, a few lipid droplets and appear as large vacuoles, these droplets are variable in size, mainly round to ovoid in shape with an irregular boundary containing material of variable electron density and small vesicles of smooth endoplasmic reticulum scattered throughout the cytoplasm. Zona fasciculata is the major portion of the adrenal cortex, its cells are large and arranged in radial cords towards the medulla, it contain a greater number of lipid droplets than those observed in the cells of glomerulosa. Zona fasciculata cells have tubular profiles of smooth endoplasmic reticulum in the form of vesicles scattered throughout the cytoplasm. In contrast to the zona glomeruolosa the cells of the zona fasciculata are rich in smooth endoplasmic reticulum.
\end{abstract}

Keywords: Bat; Adrenal cortex; Medulla; Ultra structure

\section{Introduction}

As general in all mammals, adrenal gland is composed of two distinct portions: an outer cortex and an inner medulla [15] paired right and left flat adrenal glands located to the craniomedial of the kidneys were observed in porcupine (Hystrixcristata). In human, the adrenal glands (suprarenal glands) associated with the kidneys. A gland present top on each kidney like a cap and is embedded in the mass of adipose tissue that encloses the kidney. The adrenal glands are shaped like pyramids; each gland is very vascular and consists of two parts. The central portion is the adrenal medulla and the outer part is the adrenal cortex [6]. Adrenal cortex is subdivided into three zones; the outermost zona glomerulosa that contained cells formed cords and contained lipid vacuoles, the middle thickness and palest zona fasciculata formed of large polyhedral spongiocytes which arranged in longitudinal straight cords separated by straight blood capillaries and the last third narrow zona reticularis formed of small polyhedral deeply stained cells arranged in branching anastmosing cords separated by irregular blood capillaries [7]. Adrenal medulla formed of chromaffin cells that are large polygonal and arranged either in groups around blood vessels or in branching cords. These cells secrete catecholamines (adrenaline and nor-adrenaline). One pair of adrenal glands was found in the Emballonurid bat, Taphozous longimanus against the lateral kidney, left one was pyramidal, but the right was oval. The gland has two layers, inner medulla and outer cortex which have zona glomerulosa and zona fasciculata while the third zone zona reticularis is absent [8]. Adrenal gland considered as a key organ in bat because it plays an important role in metabolism and homeostasis of animals, it protects the organism against acute and chronic stress; Catecholamine's of the medulla mobilize glucose and fatty acids for energy, muscles and lung for action in acute actress. There is a little information available on anatomy of adrenal gland of Egyptian bats. The present report reveals the anatomy of adrenal glands in Rousettus eagyptiacus.

\section{Material and Methods}

The specimen used was females non pregnant adult Frugivorous bat Rousettus eagyptiacus. Each animal was euthanized by chloroform, dissected and the adrenal gland go out, thin fixed with $10 \%$ formalin for general histology and stained with Hematoxylin and eosin stain [9].

\section{Transmission Electron Microscopy:}

For transmission electron microscope, small pieces of $1 \times 1 \mathrm{x}$ $1 \mathrm{~mm}$ of pituitary gland of bats were obtained and were rapidly processed as follow: - 


\section{a. Fixation:}

Small pieces of fresh specimens were fixed in a mixture of Formaldehyde / Glutraldehyde (4:1) at PH 7.4 at room temperature for 4 hours, and then rinsed twice in $0.1 \mathrm{M}$ phosphate buffer (15 minutes for each).

\section{b. Post-Fixation Treatment:}

Specimens were post fixed in $2.0 \%$ buffered Osmic acid for half an hour at $4^{\circ} \mathrm{C}$. The tissue specimens were then washed twice in phosphate buffer for $30 \mathrm{~min}$.

\section{c. Dehydration:}

The tissues were dehydrated in ascending grades of ethyl alcohol (50, 70, 80, 90 and 100\%) for two changes each of 15 minutes ( 2 x 15 minutes) in each grade. Specimens then cleared in propylene oxide for 2 changes $5 \mathrm{~min}$, each.

\section{d. Infiltration:}

Dehydrated tissues were initiated in 1: 1 solution of propylene oxide and epon mixture. Infiltration was continued with 1: 3 (propylene oxide: epon mixture) overnight at room temperature.

\section{e. Embedding:}

Embedding was carried out using freshly prepared araldite epon mixture in capsules pre-dried for 1-3 hours.

\section{f. Polymerization:}

The capsules were polymerized at $60^{\circ} \mathrm{C}$ and then the polymerized capsules were cured at room temperature for at least a day before attempting to section.

\section{g. Sectioning and Staining of Semithin Sections for Light} Microscopy:

Blocks were trimmed under the binocular microscope of ultra-cut Reichert jung ultramicrotome. Semithin sections of 1 $\mu \mathrm{m}$ thickness were obtained with the aid of glass knives made on Leica EM KMR (Knife marker). Semi-thin sections were stained by toludine blue and examined for general orientation with the light microscope.

\section{h. Sectioning and Staining of Ultrathin Sections for}

\section{Electron Microscopy:}

Specimens were then retrimmed to the selected region and ultra-thin section $60 \mathrm{~nm}$ thickness were cut and picked up on copper grids. Sections mounted on grids were double stained using uranyl acetate and lead citrate. Seven percent uranyl acetate solution in methyl alcohol was prepared and centrifuged at 5000 rpm for 10 minutes. A drop of uranyl acetate solution was placed on a dental wax sheet placed in a Petri-dish. Grids were then placed on the uranyl acetate drop (the surface grids loaded with section being facing the stain). Staining was done in the dark for about 20 mins.
Grids were washed in three successive glass bottles containing distilled water. After the last bath, grids were dried on a filter paper. Sections were then stained with freshly prepared lead citrate that centrifuged at $5000 \mathrm{rpm}$ for 10 minutes and used for staining for 10 minutes as in uranyl acetate, then washed with $0.02 \mathrm{~N}$ Noah and finally with freshly distilled water. The grids dried on filter paper and examined with electron microscope (TEM Philips $400 \mathrm{~T}$ at 80 Kv). Photos were made on Kodak EM sheet films; developed then enlarged and printed and investigated.

\section{Result}

\section{The Histological Structure}

In R. aegyptiacus the pair glands appear embedded at the lateral surface of each kidney covered by thick connective tissue capsule. It is oval and has two zones an outer cortex and an inner medulla (plate: 1 Figures 1 \& 2). The thickness of cortex surrounding the medulla different from region to region, so the gland oval. The cortex divided into three major zones; zona glomerulosa, zona fasciculata and zona reticularis (plate: 1 Figures $3 \& 4$ ). The medulla is present centrally and surrounded by cortex.

\section{Zona Glomerulosa}

Zona glomerulosa is the smallest zone of the adrenal cortex present beneath the capsule. This zone consists of irregular glomerular cells arranged in rods and generally found in group of cells. These cells have darkly stained nucleus, either centrally or eccentrically placed. The cytoplasm takes acidic stain and eosinophilic in nature. Numbers of lipid vacuoles are observed in the cytoplasmic matrix and blood capillaries are also observed between the clusters of acini. Zona glomerulosa is compactly associated with zona fasciculata and hence no identifying separation is observed in between these two zones (plate: 1 Figures1, 2).

\section{Zona Fasciculata}

It is an intermediate zone present beneath the zona glomerulosa and is the largest zone of the cortex present between the zona glomerulosa and zona reticularis. This zone consists of small columns of single or double rows. These cells are cubical and low columnar types with large numbers of lipid vacuoles. Nucleus is centrally situated, spherical in shape, darkly stained with welldeveloped nuclear membrane. Each cell shows spongy cytoplasm due to the presence of large number of lipid vacuoles (plate: 1 Figures 1, 2).

\section{Zona Reticularis}

It is the innermost zone of the cortex without any clear demarcation. The zona reticularis is present below the zona fasciculata and above the medulla. This zone possesses irregular cells with lightly stained cytoplasm and vesicular nuclei. The cytoplasm shows presence of few lipid vacuoles. Few blood capillaries are also observed in this zone (plate: 1 Figures 1,2 ). 


\section{Medulla}

Medulla is the innermost region of the adrenal gland. The layer has two types of cells epinepheric and non epinepheric cells (plate:1 continue Figures 6, 7 \& 8).

\section{The Fine Structure}

\section{The Zona Glomerulosa}

The cells have circular or oval nuclei bounded by a plasma membrane of uniform thickness. The lipid droplets are few from secreted type and large numbers from vacuolated types. These droplets are variable in size, mainly round to ovoid in shape. Mitochondria are many, round, some of them hypertrophy. The smooth endoplasmic reticulum is in the form of small vesicles scattered throughout the cytoplasm. (Plate: 2 Figures 1-6).

\section{The Zona Fasciculate}

This layer constitutes the major portion of the adrenal cortex. These cells are large and arranged in radial cords, one or two cells thick and lie between vascular channels which converge towards the medulla. Mitochondria are Present. The cells of zona fasciculata contain a greater number of lipid droplets than those observed in the cells of glomerulosa. These droplets from secreted type and large numbers from vacuolated types. Smooth endoplasmic reticulum in the form of vesicles scattered throughout the cytoplasm (Plate: 3 Figures 1-6). In contrast to the zona glomeruolosa the cells of the zona fasciculata are rich in smooth endoplasmic reticulum. Free ribosomes are present in the cytoplasm. The cells of fasciculata contain large dense bodies (lysosomal bodies) not observed in the cells of glomerulosa.

\section{The Zona Reticulosa}

This layer constitutes the last of the adrenal cortex. These cells are large, one or two cells thick and lie between vascular channels which converge towards the medulla. Mitochondria are Present small in numbers than zona fasciculata. The cells contain a greater number of dark lipid droplets than those observed in the cells of zona fasciculata. The nucleus small and spherical. Large number of mitochondria present. Smooth endoplasmic reticulum in the form of vesicles scattered throughout the cytoplasm (Plate: 4 Figures 1-6).

\section{The Medulla}

The, medulla consists of chromaffin cells arranged in small groups or short cords surrounded by blood capillaries and connective tissue. Some chromaffin cells have dense and large secretary granules and others have small. The nucleus small with nucleous. Mitochondia are round scattered throughout the cytoplasm and smooth endoplasmic reticulum present. The distinctive features of modularly cells are the chromaffin granules which appear as a membrane bound body of variable electron density. Some cells contain predominantly dense black granules called epinephrine cells, while others show scattered empty vesicles with small amounts of granular material lining to the inner layer or present in the lumen of the vesicles called norepinephrine cells (Plate: 5 \& 6 Figures 1-6).

\section{Explanation of Plates}

Plate: -1 (Figure 1 \& 1 (Continues))

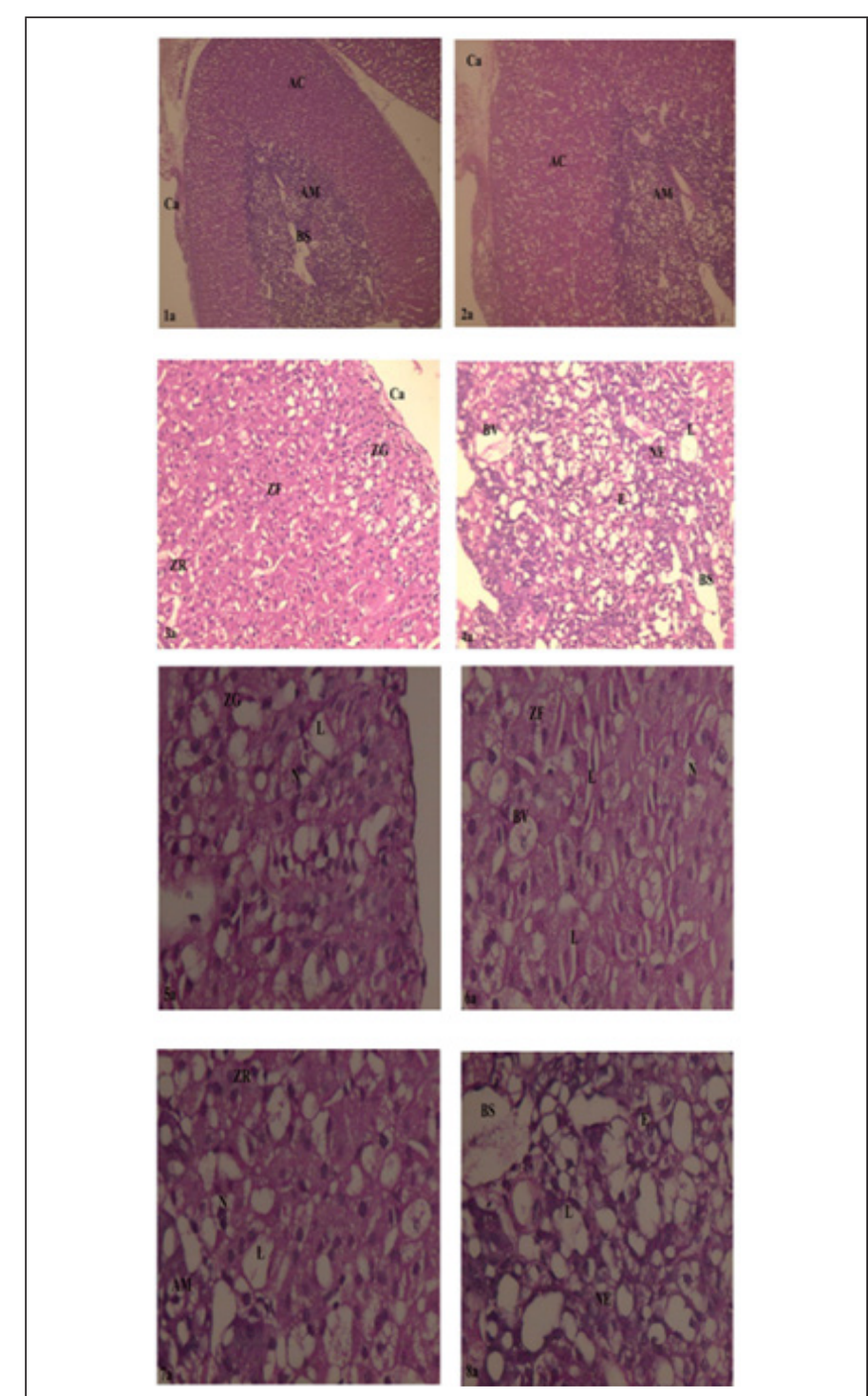

Figure 1: The structure of adrenal gland of adult Rousettus Aegyptiacus.

Figures 1a, 2a: Light micrographs of transverse section of adrenal gland shows the presence of capsule (ca) covering the gland, outer cortex (Ac) and inner medulla (AM) with Blood sinusoids (Bs) H\&E X 100.

Figures 3a-5a-6a-7a- 8a: Light micrographs of transverse section of adrenal gland shows the outermost capsule (CP). Note the cortex differentiated into outer small zone, zona glomerulosa (ZG), middle long cell cords of zona fasciculate (ZF) and inner zona reticularis (ZR), (L) lipid vacuoles, (N) nucleus H\&E X 400.

Figure 4a: Light micrograph of transverse section of adrenal gland shows the epinephrine cell of Medulla (E) and non-epinephrine (NE) H\&E X 400. 
Plate: -2 (Figure 2)
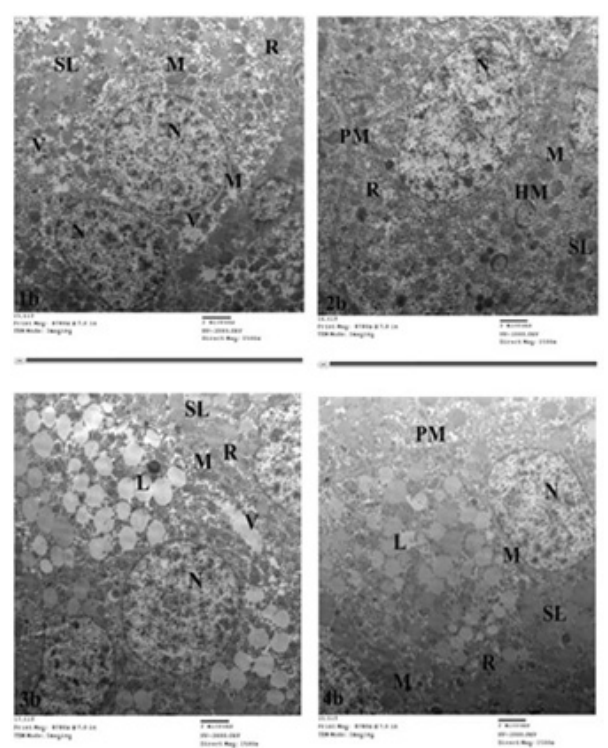

Figure 2: Ultrastructure of Zona glomerulosa of adult Rousettus Aegyptiacus.

Figure $1 \mathrm{~b}$ : Electron micrograph of the cell of zona glomerulosa showing (N) nucleus, (M) mitochondria, (SL) saturated lipids, (V) Vacuoles, (R) ribosomes.

Figure 2b: Electron micrograph of the cell of zona glomerulosa showing (N) nucleus, (M) mitochondria, (HM) hypertrophy mitochondria, (SL) saturated lipids, (V) Vacuoles, (R) ribosome's, (PM) plasma membrane.

Figures 3b, 4b: Electron micrographs of the cells of zona glomerulosa showing enormous lipids droplets (L), (N) nucleus, (M) mitochondria and $(\mathrm{HM})$ hypertrophied mitochondria, (SL) saturated lipids, (V) Vacuoles, $(R)$ ribosome's and (PM) plasma membrane.

Plate: -3 (Figure 3)
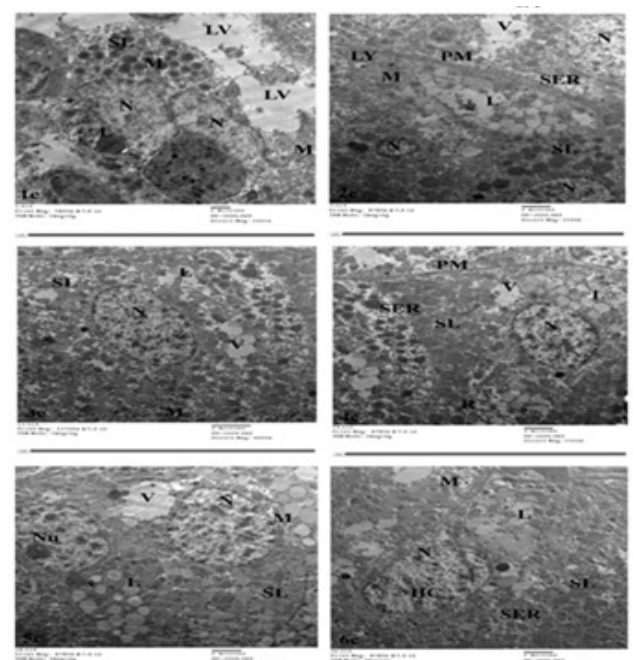

Figure 3: Ultrastructure of Zona glomerulosa of Rousettus Aegyptiacus.

Figures.1c-2c-3c-4c-5c-6c: Electron micrographs of the cells of zona fasciculata showing enormous lipids droplets $(\mathrm{L})$ and lipid vacuoles(LV), (SER) smooth endoplasmic reticulum, (N) nucleus, (M) mitochondria, (SL) saturated lipids, (V) Vacuoles, (R) ribosome's, (PM) plasma membrane, (L) lysosomes.
Plate: -4 (Figure 4)
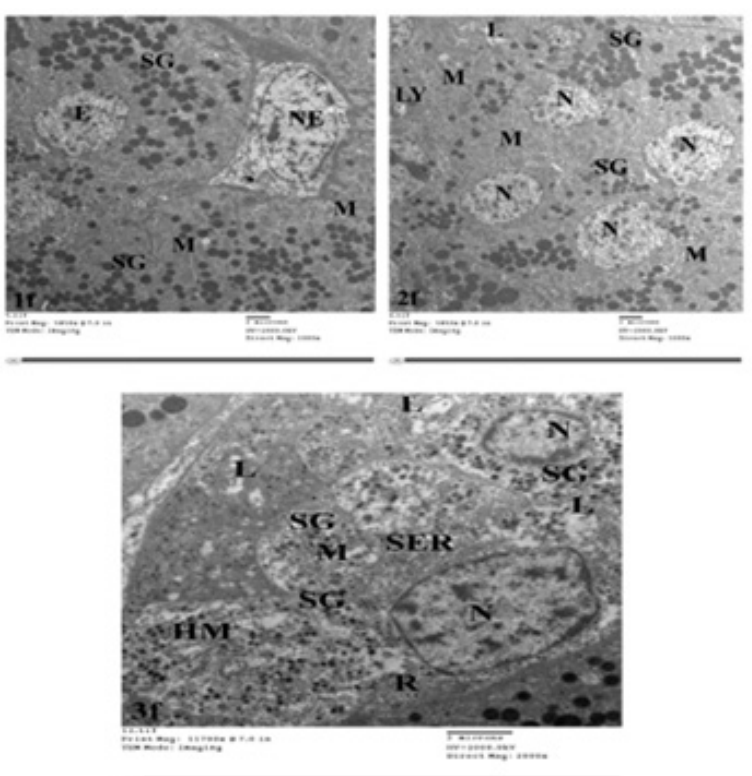

Figure 4: Ultrastructure of Zona reticularis of adult Rousettus Aegyptiacus.

Figures.1d-2d-3d- 4d: Electron micrographs of the cells of zona reticulosa showing enormous lipids droplets $(L)$ and saturated droplet (SL), (v) vacuoles, (SER) smooth endoplasmic reticulum, $(\mathrm{N})$ nucleus with nucleolus $(\mathrm{Nu}),(\mathrm{M})$ mitochondria, $(\mathrm{V})$ Vacuoles, $(\mathrm{R})$ ribosome's, $(\mathrm{PM})$ plasma membrane, $(\mathrm{L})$ lysosomes and $(\mathrm{HC})$ heterochromatin.

\section{Plate: -5 (Figure 5)}
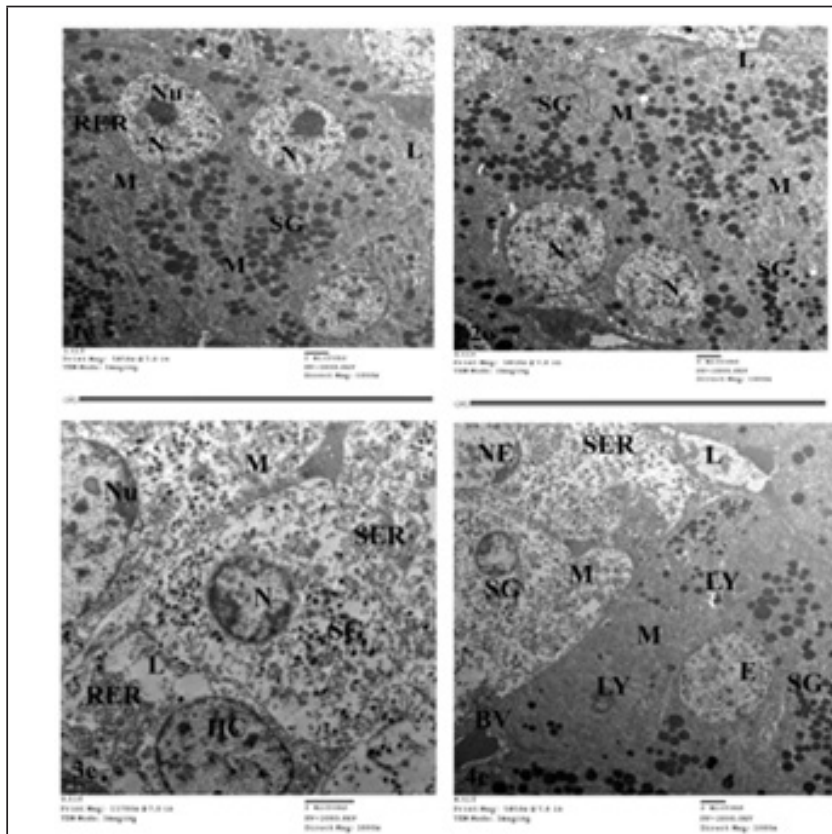

Figure 5: Ultrastructure of Norepinephrine cells of adult Rousettus Aegyptiacus.

Figures.1e-2e-3e-4e: Electron micrographs of the cells of modularly cell showing nor Epinephrine (SG) granules, rough endoplasmic reticulum (RER), ( SER) smooth endoplasmic reticulum, small and large secretary granules, $(\mathrm{N})$ nucleus with nucleolus $(\mathrm{Nu}),(\mathrm{L})$ lipid vacuoles and (LY) lysosomes. 
(Figure 6)

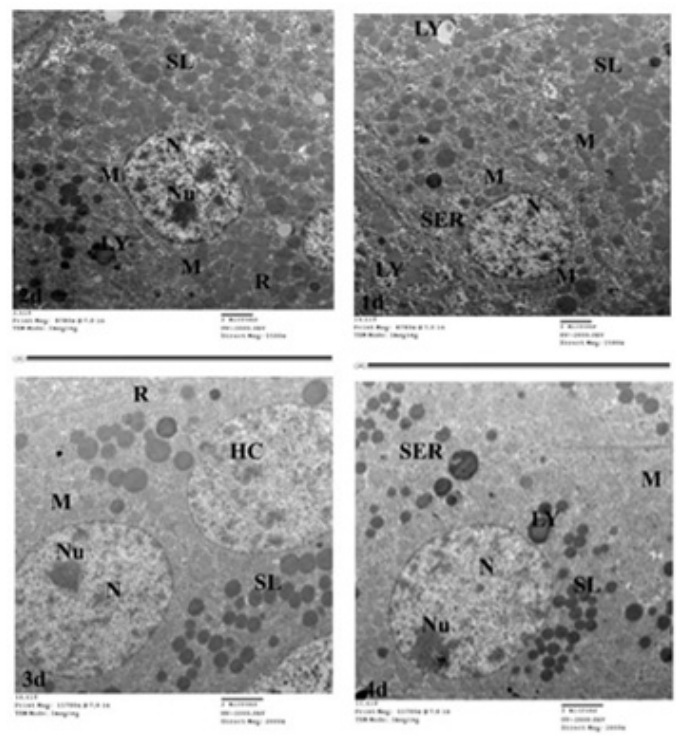

Figure 6: Ultrastructure of Epinephrine cells of adult Rousettus Aegyptiacus.

Figure 1f: Electron micrograph of modularly cells showing dark Epinephrine and light non-Epinephrine cells (SG) granules, small and large secretary granules (SG)

Figures 2f-3f: Electron micrographs of the cells of modularly cell showing Epinephrine cells (SG) granules, rough endoplasmic reticulum (RER), (SER) smooth endoplasmic reticulum, small and large secretary granules (N) nucleus, (L) lipid vacuoles, (LY) lysosomes and (HM) hypertrophied mitochondria.

\section{Discussion}

The study aims to describe the histological and the ultrastructure of the adrenal gland of Rousettus aegyptiacus. The result showed that the left and right gland oval different from Emballonurid bat, Taphozous longimanus in which the left adrenal gland is pyramidal, and the right adrenal gland is oval [8]. Adrenal gland divided into cortex and medulla, the cortex surrounding the medulla in different thickness as same to other species of mammals. According to [10], the duck cortex constitutes $68.2 \%$, the medulla $28.6 \%$ and vascular space $3.2 \%$ of the total area. The adrenal cortex is divided into three distinct zones, zona glomerulosa, zona fasciculata and zona reticularis. A distinct zone of the cortex is observed in M schereibersii [11], M lyra lyra [12], V pipistrellus [9], $P$ giganteus giganteus and $R$ leschenaultia [13], Cynopterus sphinx, $H$ lankadiva [14] and $P$ giganteus giganteus [15]. In the present species, zona reticulosa is distinct but in some species, it is present in the form of islets of cortical cells in the medullary region in $T$ melanopogon [16]. In the present study, zona glomerulosa consists of polyhedral glomerular cells which appear group of 3-7 acini or cells. Similar structure is also observed in the zona glomerulosa of Taphozous Kachhensis [17] in T longimanus, Hipposideros lankadiva [18]. In Cynopterus sphinx the cells are arranged in groups. Whereas, in Rousettus leschenaulti and Pteropus giganteus the cells are arranging in columns [19] and P giganteus giganteus [20]. The ultrastructural characteristics of the cells of zona glomerulosa of present bat adrenal gland show low numbers of vacuolated lipids and secreted lipids, circular and small nucleus. In Taphozous longimanus [21] observed some striking differences during estrus and pregnancy; Golgi apparatus is inconspicuous during estrus but well developed during late pregnancy, mitochondria show vesicular cristae during estrus and vesicular and lamellar cristae during pregnancy, moderate to high amounts of tubular profiles of smooth endoplasmic reticulum is seen during estrus. However, there is extensive development of tubular profiles of smooth endoplasmic reticulum during pregnancy. A few lipid droplets are observed in the cytoplasm during estrus, but large numbers of lipid droplets of various size and electron density are seen in the cytoplasm during pregnancy. Similar observations are reported in the glomerulosa cells of bat, H lankadiva during estrus and pregnancy [22] and during hibernation and arousing of dormouse, Muscardinus avellanarius [23] supporting present observations. Ultra-structure of the zona fasciculata of present animal characterized by secreted lipid droplet and sooth endoplasmic reticulum but in bat, $T$ longimanus shows presence of vesicular smooth endoplasmic reticulum, vacuolated lipid droplet [21]. The modularly cells of the present animal characterized by large numbers of dens large secretary granules and dense small secretary granules, rough and smooth endoplasmic reticulum in both nepherin and epinepherin cells. Different from the case of $T$ longimanus, the medullary cells are characterized by the presence of well-developed Golgi apparatus, rough endoplasmic reticulum, large number of mitochondria and chromaffin granules and similar in rat shows two types of chromaffin cells as described in rat medulla [24]. Nor epinephrine cells are predominant in the medulla of pregnant bat while epinephrine cells are predominant in the medulla of estrus bat. The present observations suggest that two cell types are present in bat species like that observed in mammals [25-28].

\section{References}

1. Banks W J (1993) Applied Veterinary Histology. Third ed., Moss by-Year Book, Philadelphia, pp. 416-423.

2. Dellman N D (1993) Textbook of Veterinary 64 International Journal of Biotechnology and Biosciences Histology. Fourth ed., Lea and Febiger, Philadelphia pp. 280-282.

3. Gude W D, G E Cosgrove, G P Hirsch (1982) Histological Atlas of the Laboratory Mouse, Plenum press, New York and London, p. 17-18.

4. Gretchen L H (1974) Animal tissue technique. Fourth edition.

5. Junqueira L C J, Carneiroand Kelley O R (1995) Basic Histology. Eighth ed., Appleton and Lange, Toronto, USA, pp. 387-397.

6. Shier D, Butler J Lewis R (2007) Hole's Human Anatomy and Physiology. (11 ${ }^{\text {th }}$ edition), McGraw- Hill publication, pp. 510.

7. Yilmaz S, Girgin A (2005) Light and electron microscopic observations on the structure of the porcupine (Hystrixcristata) adrenal gland. Veterinarski Arhiv 75(3): 265-272.

8. Shende V A, Patil K G, Janbandhu K S (2014) ANATOMICAL STUDY OF ADRENAL GLAND OF EMBALLONURID BAT, TAPHOZOUS LONGIMANUS (HARDWICKE- 1852) Int J Biotech Biosci, ISSN 2231-0304 Vol 4(1): 6265.

9. Saidapur SK, Nadkarni VB (1976) Endokrinologie 67: 244-247. 
10. Cronshow J, Holmes WV Loebes's L (1974) Fine structure of the adrenal gland in the duck. (Anas platyrhynchos). Anatomical Rec 180(2): 385406.

11. Planel H, Guilhem A, Soleilhavoup JP (1961) The cycle annual du cortex surrenal the semi-hibernant: Miniopterus schreibersii. Accounts of the Association of Anatomists 47: 620-633.

12. Bhima Rao BS, Devaraj Sarkar HB (1975) Histology of adrenal gland of the Indian false vampire bat, Megaderma lyra lyra. Cur Sci 44: 87-94.

13. Sapkal VM (1977) The adrenal gland of two species of fruit bats. Current Science 47(4): 140-142.

14. Dhamani AA (2004) Endocrinology of reproduction in male leaf-nosed bat, Hipposideros lankadiva (Kelaart). Ph. D. Thesis, Nagpur University, Nagpur.

15. Papadkar JN, Dhamani AA (2012) Seasonal changes in the adrenal gland of the Indian male fruit bat pteropus giganteus giganteus (Brunnich) during the reproductive cycle.

16. Lowary ML, Lall SB (1987) Evidence for the involvement of the adrenal gland in the gestation junction of Taphozous melanopogon (Chiroptera) displaying absolute dextral dominance of genital tract. European Bat Research, Charles Uni Press, Praha. 161-169.

17. Bansod Deepak S, Chavhan Pankaj R, Dhamani Amir A (2018) Morphohistological studies on the adrenal gland in male and female bat, Taphozous Kachhensis (Dobson) Special Issue A 12: March 2018:215225 UGC Approved Journal No 48951 Original Article Open Access National Seminar on Modern Perspectives in Life Sciences (MPLS-2018) | 215.

18. Widmaier EP, Kunz TH (1993) Basal, diurnal and stress induced levels of glucose and glucocorticoids in captive bats. J Exp Zool 265(5): 533-540.

19. Sapkal VM (1978) The adrenal gland of two fruit bat. Curr Sci 47(4): 140-142.
20. Papadkar JN, Dhamani AA (2012) Seasonal changes in the adrenal gland of the Indian male fruit bat pteropus giganteus giganteus (Brunnich) during the reproductive cycle.

21. Nerkar, M M Gadegone (2012) The Fine Structure of the Adrenal Gland of the Indian Sheath- Tailed Bat, Taphozous longimanus (Hardwicke Journal of Pharmacy and Biological Sciences (IOSR-JPBS) ISSN: 22783008. 3(3): 9-13.

22. E. Seraphim (2004) Endocrine interaction during different phases of the female reproductive cycle in Hipposideros lankadiva (Kelaart), doctoral diss., RTM Nagpur University, Nagpur (India).

23. C Zancanaro, M Malatesta, P Vogel, S Fakan (1997) Ultra structure of the adrenal cortex of hibernating, arousing and euthermic dormouse, Muscardinus avellanarius. Anatomical Record 249(3): 359-364.

24. G Brown, L Grota, D Penney, S Reichlin (1970) Pituitary adrenal function in the squirrel monkey. Endocrinology 86(3): 519-529.

25. R Coupland (1965) Electron microscopic observations on the structure of the rat adrenal medulla I, The ultrastructure and organization of chromaffin cells in the normal adrenal medulla. Journal of Anatomy 99: 231-254.

26. R Brenner (1966) Fine structure of adrenocortical cells in adult male rhesus monkeys. American Journal of Anatomy 119(3): 429-453.

27. R Coupland, B Weakley (1968) Developing chromaffin tissue in the rabbit: an electron microscopic study. Journal of Anatomy 102(3): 425455 .

28. A Belloni, G Mazzocchi, F Mantero, G Nussdorfer (1987) The human adrenal cortex: ultrastructure and base-line morphometric data. Journal of Submicroscopy and Cytology 19(4): 657-668. 